\title{
openheart Direct emergency medical services transport in STEMI: breaking the bank for non-PCI capable hospitals?
}

\author{
Jacqueline L Green, Brahmajee K Nallamothu
}

To cite: Green JL, Nallamothu BK. Direct emergency medical services transport in STEMI: breaking the bank for non-PCl capable hospitals?. Open Heart 2014;2:e000139. doi:10.1136/openhrt-2014000139

Accepted 21 July 2014

\section{Linked}

- http://dx.doi.org/10. 1136/openhrt-2014-000042

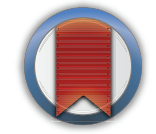

CrossMark

Division of Cardiovascular Medicine, University of Michigan, Ann Arbor, Michigan, USA

Correspondence to Dr Jacqueline L Green; gjacquel@umich.edu
Direct emergency medical services (EMS) transport of patients with ST-elevation myocardial infarction (STEMI) to a percutaneous coronary intervention (PCI)-capable hospital is emerging as an effective strategy to improve care and reduce costs. This approach has been shown to improve mortality, ${ }^{1}$ decrease time to reperfusion, ${ }^{2}$ and reduce overall costs. ${ }^{3}$ Accordingly, the 2013 updated American Heart Association/ American College of Cardiology (AHA/ ACC) Guidelines for STEMI management now include a class I recommendation for direct EMS transport to a PCI-capable hospital for patients with STEMI, ${ }^{4}$ and EMS systems of care are maturing to facilitate this approach. Despite these important trends, however, some communities remain reluctant to implement direct EMS transport for various reasons. The study by Pathak et a $\check{P}$ published in Open Heart provides critical insight into one of the most frequently-cited concerns raised by skeptics: revenue loss at non-PCI capable hospitals as lucrative cardiovascular services are diverted away. ${ }^{6}$

Opponents to direct EMS transport have long perceived the practice will financially jeopardise smaller hospitals in rural and underserved communities given the large role cardiovascular services play in subsidising less reimbursed care. Pathak et al respond to this assertion with an interesting analysis of Florida's hospital discharge data from 2006. The Florida Agency for Health Care Administration includes all discharge claims from $100 \%$ of Florida hospitals due to statewide mandatory reporting. The authors defined hospitals susceptible to losing patients through direct EMS transport as STEMI referral hospitals. These were facilities that did not perform PCI procedures on inpatients or those that performed fewer than 200 PCIs annually. By dividing all adjusted charges for patients with a primary discharge diagnosis of STEMI (using International Classification of Diseases-9 diagnostic codes) by all adjusted charges for all hospital inpatients, the authors created a metric of projected revenue loss-assuming all inpatient revenue from patients with STEMI would be lost if direct EMS transport had been instituted universally across the state.

Several findings reported by the authors are noteworthy. In the primary analysis, average projected revenue losses from cardiovascular services at most STEMI referral hospitals were estimated to be minimal. Indeed, on average STEMI referral hospitals in the state had projected revenue losses of just $\$ 0.33$ for every $\$ 100$ of total patient revenue. Furthermore, the five hospitals with the greatest projected revenue losses from proposed direct EMS transport were all located in metropolitan areas with a high-volume PCI centre within $30 \mathrm{~min}$ driving distance. Only $9 \%$ of STEMI referral hospitals were rural and a mere 5\% offered PCI. These findings challenge the assumption that small, rural hospitals in underserved communities will suffer by participating in a regionalised STEMI system of care that encourages direct EMS transport.

Yet the primary analysis did not incorporate patients with non-STEMI with acute coronary syndrome (ACS), who also may impact the economics of STEMI referral hospitals. To address this concern, Pathak et al performed a sensitivity analysis focused on a 'worst-case' scenario where STEMI referral hospitals lost revenue from all patients with ACS. Even here they found negligible $(<2 \%)$ losses in revenue, suggesting these facilities should expect little financial impact if they participate in a regionalised STEMI system of care that supports direct EMS transport and should be able to continue to provide essential services in other clinical areas. 
Several limitations to the data source analysed merit discussion and should caution readers in interpreting these findings. First, these analyses only evaluated inpatient revenue, and did not include potential losses for subsequent outpatient care. Patients may prefer to arrange their outpatient care, such as cardiac catheterisations, imaging and follow-up appointments, at the hospital where they initially received ACS care. These patients are not captured in hospital claims, and thus, this is an important uncertainty that future work will need to consider. Second, administrative data are notoriously inaccurate at discriminating between patients with STEMI and patients with non-STEMI and thus cannot capture who may be eligible for reperfusion therapy. ${ }^{7}$ That said, the authors' analysis of the broader group of patients with ACS is reassuring as it should not be affected by this concern. A third limitation is the time lag in data sources. Trends in procedure revenues and referral patterns in 2006 are of less clear relevance in 2014, given that local STEMI networks evolving in Florida over the last decade resulted in a dramatic increase (from $62.4 \%$ to $89.7 \%$ ) in the proportion of STEMI patients initially hospitalised at a PCI capable facility. ${ }^{8}$ Thus these analyses potentially describe hospitals that were sufficiently financially diverse at baseline to survive the initial transition toward regionalisation of STEMI services already underway in Florida. Fourth, because considerable geographic variation in cardiovascular procedure use $^{9}$ and the distribution of PCI-capable hospitals exists nationally, ${ }^{10}$ it remains unclear how applicable the findings are for patients outside of Florida.

Ultimately, any discussion regarding costs in the USA also deserves consideration of the rapidly changing landscape of reimbursement accompanying the landmark Affordable Care Act (ACA) that was signed into law in March 2010. Such changes may impact direct EMS transport in multiple ways. For example, almost twice as many hospital mergers existed in 2012 as compared with $2006 .{ }^{11}$ As hospitals merge into larger health systems in response to ACA and other policies, an opportunity arises for PCI-capable hospitals to lead a comprehensive regionalised system of emergency cardiovascular care that includes direct EMS transport. Also since 2006, accountable care organisations (ACO) have emerged and now encompass $14 \%$ of the US population. ${ }^{12}$ ACOs strive to deliver care more efficiently through the development of networks of care. Finally, the insurance market place is shifting dramatically with the implementation of the ACA. An estimated 20 million Americans have gained insurance coverage, and all plans are required to meet certain benefits standards. ${ }^{13}$ In response to the growing demand for accountability, insurers are implementing strategies, such as value-based purchasing and bundled payments, that have the potential to financially incentivise timely and effective care like reperfusion.
We believe the multitude of changes in reimbursement and healthcare organisation since the time of this analysis in 2006 only serve to strengthen financial incentives for hospitals within regionalised systems of STEMI care. Pathak et al offer unique clarity into the hospital characteristics and finances of potential STEMI referral hospitals that chose to participate. Their work suggests most of these hospitals are in metropolitan areas and are not likely to suffer significant revenue losses from direct EMS transport. Such evidence should reassure regions that are developing better and more organised STEMI systems of care that they can broaden the reach of timely reperfusion with primary PCI without breaking the bank for small, rural hospitals.

\section{Competing interests None.}

Provenance and peer review Commissioned; internally peer reviewed.

Open Access This is an Open Access article distributed in accordance with the Creative Commons Attribution Non Commercial (CC BY-NC 4.0) license, which permits others to distribute, remix, adapt, build upon this work noncommercially, and license their derivative works on different terms, provided the original work is properly cited and the use is non-commercial. See: http:// creativecommons.org/licenses/by-nc/4.0/

\section{REFERENCES}

1. Le May MR, Wells GA, So DY. Reduction in mortality as a result of direct transport from the field to a receiving center for primary percutaneous coronary intervention. J Am Coll Cardiol 2012;60:1223-30.

2. Fosbol EL, Granger CB, Jollis JG. The impact of a statewide pre-hospital STEMI strategy to bypass hospitals without percutaneous coronary intervention capability on treatment times. Circulation 2013;127:604-12.

3. Concannon TW, Kent DM, Normand SL, et al. Comparative effectiveness of ST-segment-elevation myocardial infarction regionalization strategies. Circ Cardiovasc Qual Outcomes 2010:506-13.

4. O'Gara PT, Kushner FG, Ascheim DD, et al. 2013 ACCF/AHA guideline for the management of ST-elevation myocardial infarction. J Am Coll Cardiol 2013;61:e78-140.

5. Pathak EB, Comins MM, Forsyth CJ, et al. Routine diversion of STEMI patients to high-volume $\mathrm{PCl}$ centers: modeling the financial impact on referral hospitals. Open Heart 2015;2:e000042. doi:10.1136/openhrt-2014-000042

6. Moyer P, Ornato JP, Brady WJ, et al. Development of systems of care for ST-elevation myocardial infarction patients: the emergency medical services and emergency department perspective. Circulation 2007;116:e43-8.

7. Woo KS, Ghali WA, Southern DA, et al. Feasibility of determining myocardial infarction type from medical record review. Can J Cardiol 2008;115-17.

8. Forsyth CJ, Pathak EB, Stom JA. De Facto regionalization of care for ST-Elevation myocardial infarction in Florida, 2001-2009. Am Heart J 2012;164:681-8.

9. Matlock DD, Groeneveld PW, Sidney S, et al. Geographic variation in cardiovascular procedure use among Medicare fee-for-service vs Medicare advantage beneficiaries. JAMA 2013;310:155-62.

10. Langabeer JR, Henry TD, Kereiakes DJ, et al. Growth in percutaneous coronary intervention capacity relative to population and disease prevalence. J Am Heart Assoc 2013;2:e000370.

11. Creswell J, Abelson R. New laws and rising costs create a surge of supersizing hospitals. The New York Times. 12 August 2013

12. Gold, Jenny. FAQ on ACOs: accountable care organizations, explained. Kaiser Health News. http://www.kaiserhealthnews.org/ stories/2011/january/13/aco-accountable-care-organization-faq.aspx (accessed 23 May 2014).

13. Blumenthal D, Collins SR. Health care coverage under the affordable care act-a progress report. $N$ Engl J Med 2014;371:275-81. 